\title{
Establishing vegetated foreshores to increase dike safety along lake shores
}

\author{
Ellis Penning ${ }^{1, a}$, Henk Steetzel ${ }^{2}$, Robbin van Santen $^{2}$, Marieke de Lange $^{3}$, Sonja Ouwerkerk ${ }^{4}$, Vincent Vuik ${ }^{4}$, Jasper Fiselier ${ }^{5}$ \\ and Jaap van Thiel de Vries ${ }^{6}$ \\ ${ }^{1}$ Deltares, Ecosystems and Water Quality, Boussinesqweg 1, 2600 MH Delft, the Netherlands \\ ${ }_{2}^{2}$ Arcadis, Hanzelaan 286, $8017 \mathrm{JJ}$ Zwolle, the Netherlands \\ ${ }^{3}$ Alterra, Droevendaalsesteeg, 6708 PB Wageningen, the Netherlands \\ ${ }^{4} \mathrm{HKV}$ lijn in water, Botter 11-29, $8232 \mathrm{JN}$, Lelystad, the Netherlands \\ ${ }^{5}$ RoyalHaskoningDHV, Laan 1914 35, 3818 EX Amersfoort, the Netherlands \\ ${ }^{6}$ Ecoshape, Burgemeester de Raadtsingel 69, 3311 JG Dordrecht, the Netherlands
}

\begin{abstract}
Vegetated foreshores in front of existing dikes can contribute to the overall reduction of wave loads on the dike. In order to test this concept in large shallow lakes a field pilot was constructed along the Houtribdijk in Lake Markermeer (the Netherlands) in 2014 to gain experience with construction, stability, maintenance and governance aspects. A large scale monitoring programme was set up to follow the hydrodynamic forcing, morphological changes and vegetation development on the pilot. The pilot is located on an exposed south-westerly direction, and experiences substantial wave impact. As a result the desired vegetation on the land-water interface has not been able to establish, but a rather dynamic sandy beach is currently the main feature along the waterline of the site. Higher up the slope planted reeds, and a mixture of willows has well established itself in the first growing season. The exposed position of the location makes that hardly any natural pioneer vegetation has settled, only in small sheltered areas some annuals were able to germinate and maintain themselves.
\end{abstract}

\section{Introduction}

Vegetated foreshores, such as salt marshes and mangroves are commonly occurring in deltaic systems where tides play a role in the sediment dynamics of the location $[1,2]$. These foreshores create additional safety against flooding, as they are able to reduce incoming wave energy and withstand erosive forces [3,4]. More and more they are therefore included in safety assessments and flood management.

In large shallow lakes similar situations may exist where vegetated foreshores, consisting of reed beds dampen wave attack on the shoreline [5-7]. However, in the Netherlands the large shallow lakes are bordered by large dikes to protect the low lying land behind it. Many of these dikes need upgrading in face of changing climate and new safety requirements [8].

The upgrading of these dike systems can be done with traditional often costly methods, but taking the knowledge of the coastal vegetated foreshores as inspiration, new methods are being considered, including newly constructed vegetated foreshores.

However, the large lakes in the Netherlands are characterized by a fixed and unnatural low water level in winter for safety reasons and high water level in summer for fresh water supply, exposing such foreshores to a very different hydrodynamic forcing when compared to the (tidal) saltmarsh systems. Most plant species do not flourish under such conditions. Since knowledge on the behaviour of newly created foreshores is scarce, a large scale pilot project was constructed to gain insight in the most prominent aspects of designing and implementing these foreshores in front of the dikes of large, shallow inland lakes with a managed water level.

This paper describes the current state of the pilot, which was constructed in 2014 and will be monitored up to 2018 , and focusses primarily on the relation between incoming hydrodynamic forcing, the morphological changes and the development of vegetation on the foreshore.

\section{Methods}

During the summer of 2014 a field pilot natural foreshore was constructed in front of the Houtribdijk, in Lake Markermeer, the Netherlands (figure 1). Lake Markermeer $(700 \mathrm{~km} 2)$ has a fetch of up to $40 \mathrm{~km}$, and is on average 2-4 $\mathrm{m}$ deep, with sections up to $9 \mathrm{~m}$ deep in the south-eastern area of the lake. The lake has an unnatural water level fluctuation with average water levels set to -0.2 m NAP (Normalized Amsterdam Water Level, equals the mean sea level in the region) in summer and $-0.4 \mathrm{~m}$ NAP in winter.

\footnotetext{
${ }^{a}$ Corresponding author: ellis.penning@deltares.nl
} 

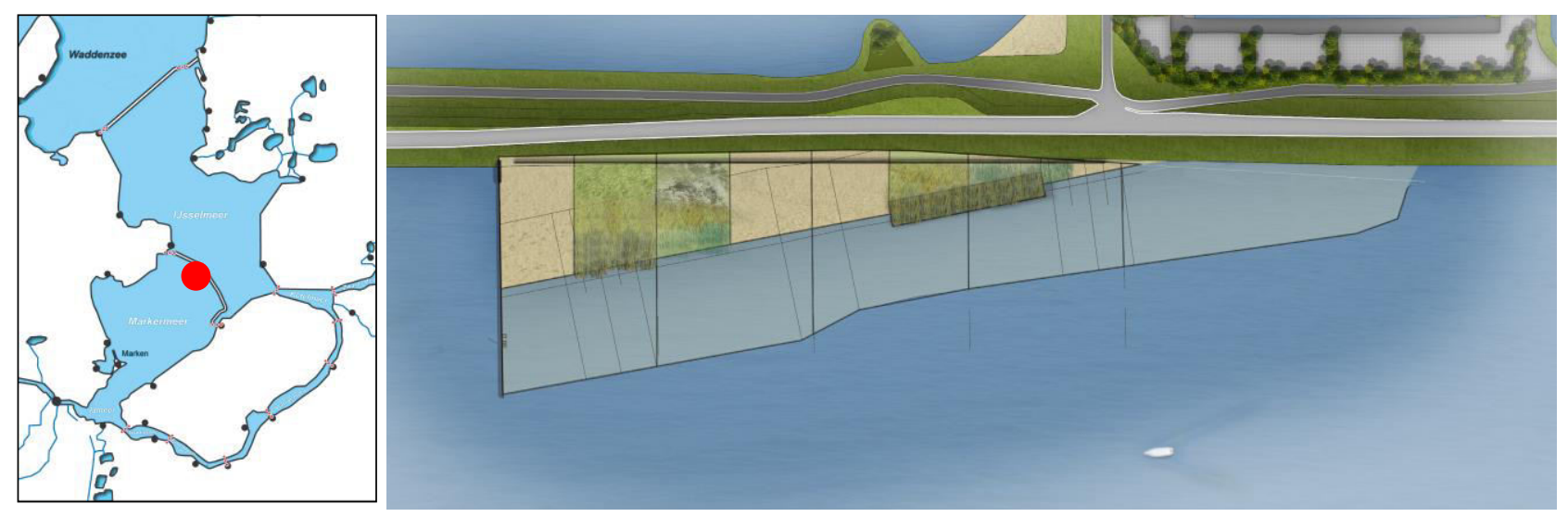

Figure 1 Left: location of the pilot (red dot); right: lay-out of the pilot in Lake Markermeer with four sections of each $100 \mathrm{~m}$ wide, and each section half planted manually, while the other half is left to develop on its own. The willow mats are located in the southern end of the pilot on the waterline.

The widest section of the foreshore was designed to withstand storm events with a 10 year return period (water level $0.55 \mathrm{~m}+\mathrm{NAP}$, wave heights of $1.2 \mathrm{~m}$ with peak periods of $5 \mathrm{~s}$ and a general incoming wave direction of about 213 degrees).

Based on these conditions a design slope of 1:30 was chosen with a maximum crest height of the fore shore of 1,23 m +NAP in order to account for wave run up (calculations based on the official Dutch technical standards for wave run up, as defined in [9]). This design slope and sand body was created by applying approximately $70,000 \mathrm{~m}^{3}$ of locally sourced sand using traditional sand nourishment techniques. At the northern end the foreshore is enclosed by a sheet pile wall.

The pilot was divided into four test sections of each $100 \mathrm{~m}$ wide perpendicular to the dike and a fifth residual section completely below the water line that was not used in the monitoring of the vegetation development.

Two sections received a layer of clay carefully mixed through the top $50 \mathrm{~cm}$ sand layer to achieve a sand/clay mixture of 70:30 ratio to assess if this would stimulate vegetation development compared to applying sand only. Six exclosures were placed on the pilot, three of which in planted sections, three of which in bare sections to monitor the effect of grazing by geese.

A $100 \mathrm{~m}$ longshore and $16 \mathrm{~m}$ wide willow branches mat was installed on the shoreline of section 3 and 4 in order to assess if such a mat would be able to help the establishment of reed vegetation in the shore zone.

A wind screen was constructed parallel to the dike in order to prevent aeolian sand transport onto the dike from the pilot.

In April 2015 vegetation was planted in half of the 4 sections, with the other half of each section left bare. Planting consisted of mixed willow species on the areas higher than $0.5 \mathrm{~m}+$ NAP (normally not affected by high water levels), and of common reed from $0.5 \mathrm{~m}+\mathrm{NAP}$ down to the shore line (area that can be affected by high water levels due to wind-setup). This vegetation was well watered in the first month after planting to avoid desiccation.

\subsection{Monitoring programme}

In September 2014 a continuous monitoring campaign has started that will last until March 2018. A monitoring station was installed on the sheet pile wall consisting of a meteorological station (wind speed, wind direction, temperature, air pressure, and precipitation), a water level meter and two photo cameras (one wide-angle and one tele-lens system). Hundred meters off shore, directly in front of the test section in the open water a Nortek Vector was placed in an underwater frame to record the incoming waves. Data is recorded hourly on a data logger and send via GPRS to an Open Earth Data Repository Server, from where it is further processed for analyses.

Starting from the $18^{\text {th }}$ of September 2014, monthly field visits were carried out in the first year to record the morphological changes on the pilot using dGPS (Leica Viva GS14/GS10 GNSS system with base station). Transects of $15 \mathrm{~m}$ apart were surveyed. On land and in the very shallow zone (up to $1 \mathrm{~m}$ deep) the dGPS was placed on a roller construction, on the deeper water echosounding equipment was placed on a jetski (Hydrobox Single Beam Echo Sounder, SBES, measuring frequency $10 \mathrm{~Hz}$ ) ensuring overlap between the tracks of both instruments. Sediment samples were taken both above water (1x per half year) and below the water at three different depths (every field visit) to be analysed for grain size distribution and chemical composition.

General subsidence of the entire pilot was measured by beacons that were installed during the construction phase. The levels of these beacons are measured with dGPS to monitor the general subsidence of the subsoil due to the load of the sandy foreshore.

Groundwater level fluctuations were recorded using 7 standard ground water level divers installed at various locations at the pilot from the dike towards to water line.

Vegetation development was monitored by field visits in early spring and mid-summer using an evenly spaced layout for a total of 65 permanent quadrants (PQs), in which species composition and species abundance was recorded. During these visits the groundwater level divers are also logged.

Every September the monitoring station and its equipment, including the Nortek Vector are serviced to be ready for the next winter storm season. 


\subsection{Analyses}

Meteorological data was checked for consistency by comparing the data with data from other wind stations in the area. Water level pressure data was corrected with the air pressure data and incoming wave data was transformed using the maximum entropy method (Auke Process version 9.0.4) after filtering outliers and low frequency components $(0.15+\mathrm{Hz})$ taking into account the air pressure variations.

The dGPS data was merged with data from the echo sounder and transformed to xyz files, which were further interpolated to detailed digital elevation maps (DEMS). These were further analysed in depth for changes in the cross-sectional morphological development, while the full DEMS were compared to understand pilot-wide sand transport processes. Grain size analyses were carried out on a Coulter LS230 laser grain-sizer with a 5 MW 750 nm laser beam.

Vegetation development was also followed by classifying SPOT satellite images from 12 march and $9^{\text {th }}$ September 2015 for the Normalized Difference Vegetation Index (NDVI) which represents a measure of 'greenness' of the vegetation to monitor differences in development between the sections with only sand and sections with the sand/clay mixture.

\section{Results}

\subsection{General observations}

The pilot has been operational now for almost 2 years. The willow mats have not been able to withstand the strong incoming waves and have been lost. Vegetation planted in the shore zone has not been able to establish itself due to the heavy waves and repeatingly shifting shoreline. Vegetation higher up the slope was able to establish itself, although grazing by geese hampered the development of the young reed plants outside the exclosures. The wind screen has played a major role in preventing aeolian sand transport onto the dike, which was clearly visible at locations where the screen became damaged. In those locations immediately sand started to be transported onto the dike.

\subsection{Hydrodynamic forcing}

The recorded water levels in the lake are linked to the overall water level management in the general seasonal trends with summer water levels around $-0.2 \mathrm{~m}$ NAP and winter water levels around $-0.4 \mathrm{~m} \mathrm{NAP}$, but also experiences direct response to wind driven water level setup. These wind driven water level set up events are rapid and short, with high water levels $(>0$ m NAP) lasting often less than $24 \mathrm{hrs}$ and occurring at irregular intervals.

The prevailing wind direction is from the South West, and especially high wind speeds almost only occur in combination with directions between South West and North West (figure 2) and water levels are linked to this. Wave heights are also a direct response to the wind conditions and waves are higher at higher water level set up with maximum incoming wave heights of up to $1.2 \mathrm{~m}$ with a water level set up of up to $0.45 \mathrm{~m}$ compared to the mean water level in the lake (figure 3).

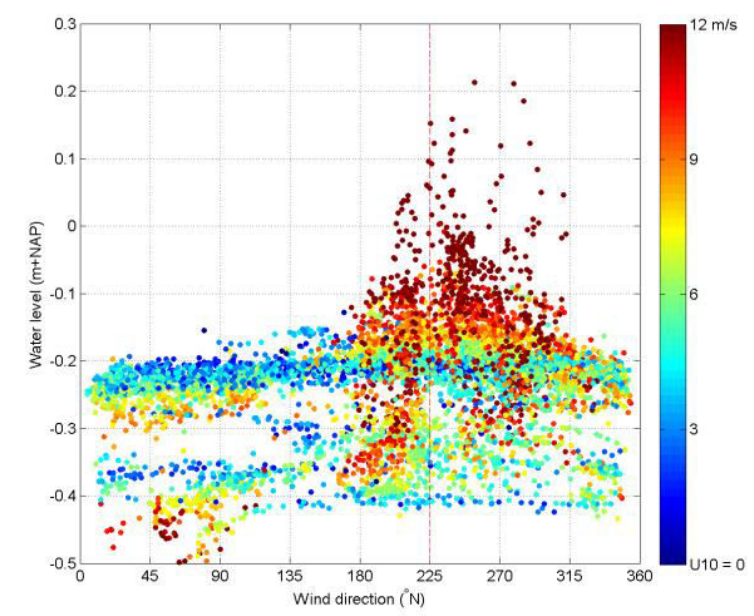

Figure 2. Relationship between wind direction, water levels and wind speed (colour bar). Clearly visible at low wind speeds are the managed reference water levels of $0.2 \mathrm{~m}-\mathrm{NAP}$ (summer water level) and $0.4 \mathrm{~m}-\mathrm{NAP}$ (winter water level).

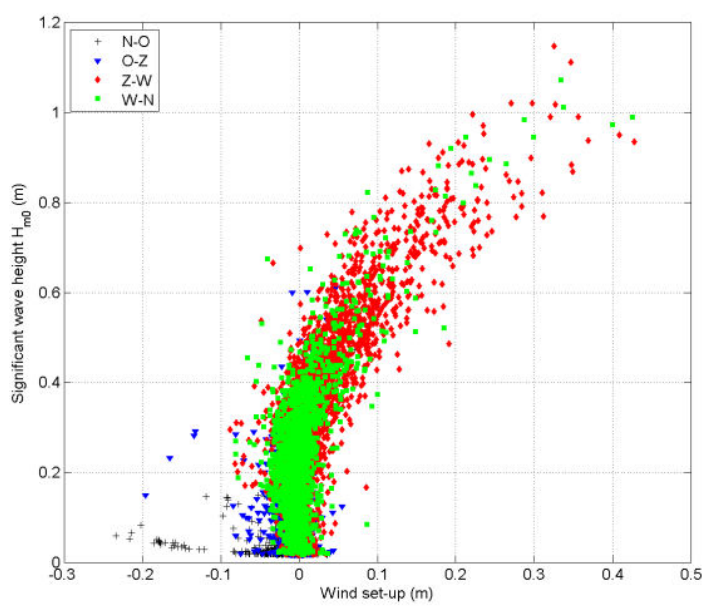

Figure 3. Wind driven water level setup and significant wave height for the four main wind directions NO-North-East, OZ South East, ZW, South West, WN - North West.

\subsection{Morphological changes}

\subsubsection{General morphological developments}

The pilot experiences dynamic rotation of the shore line around a central point depending on the direction of the incoming waves. During storms the orientation of the shoreline can change rapidly (order of days) (figure 4) with large excursions of the shoreline around point $\mathrm{A}$ and $\mathrm{C}$ with the pivotal axis in point $\mathrm{B}$. 


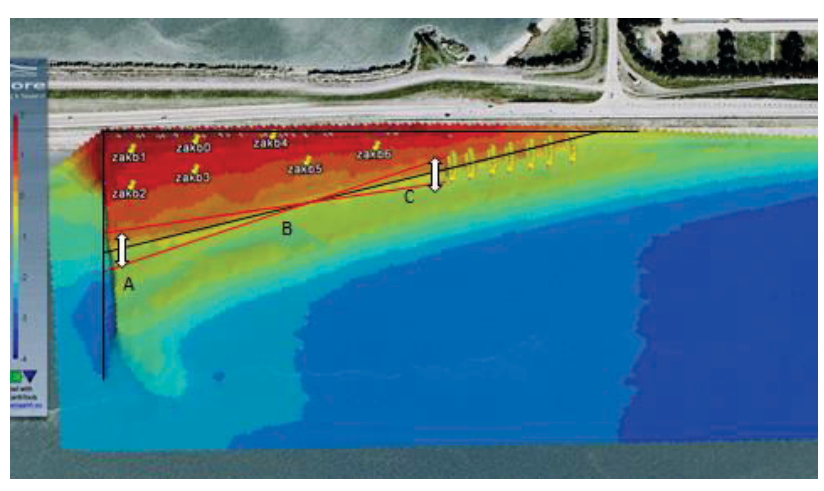

Figure 4. General overview of the morphology of the pilot with an average shoreline in black, and the dynamic shoreline in red. Excursions of the shoreline from the average are highest in location $\mathrm{A}$ and $\mathrm{C}$ and lowest in location $\mathrm{B}$.
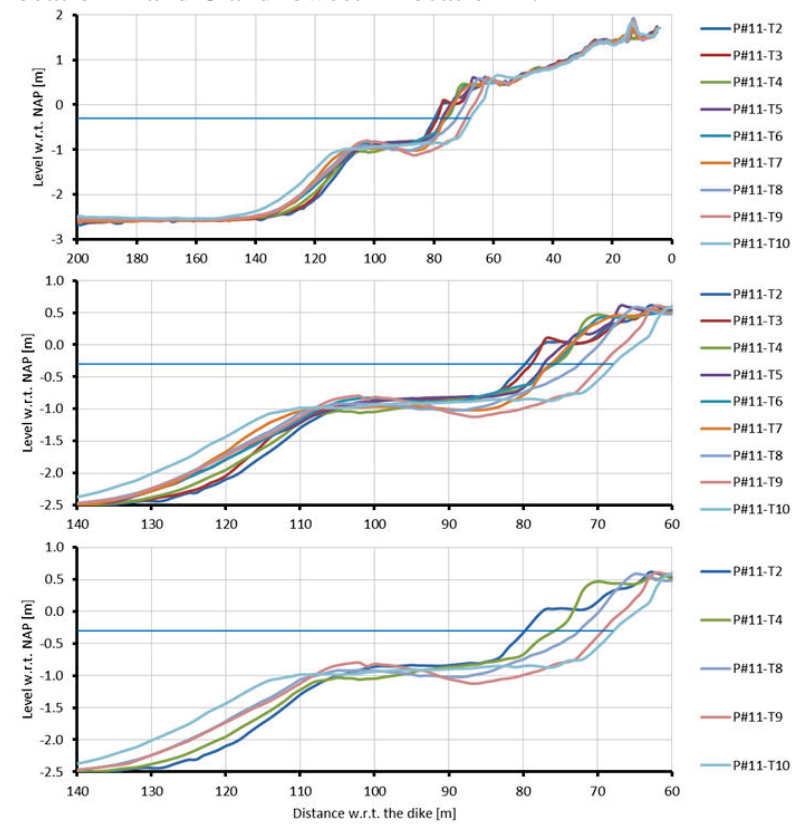

Figure 5. Cross sectional dynamics in the shoreline/of 8 cross sections for all field visits (T1 - first visit in Sept. 2014, T 10 last visit in January 2016), with a clear underwater plateau, a steep shore line zone and a swash bar around $+0.5 \mathrm{~m}$ NAP.

Taking a cross section overview in this central area of the pilot and plotting all transects over time it is clearly visible that the pilot quickly developed a shallow under water plateau with a depth of approx. 0.8 to 1,0 m - NAP, a steep slope (approx. 1:10) along the water line, and a small swash bar around $0.5 \mathrm{~m}+\mathrm{NAP}$ (figure 5).

\subsubsection{Sediment composition}

The sand used in the construction of the pilot has a very variable grain size with batches with a D50 of 150 $\mu \mathrm{m}$ to $600 \mu \mathrm{m}$ and D90 up to $1,200 \mu \mathrm{m}$. Wave action has led to a sorting of sand in the underwater section of the pilot with finer sands in the deeper areas and coarse sand along the shore line (figure 6).

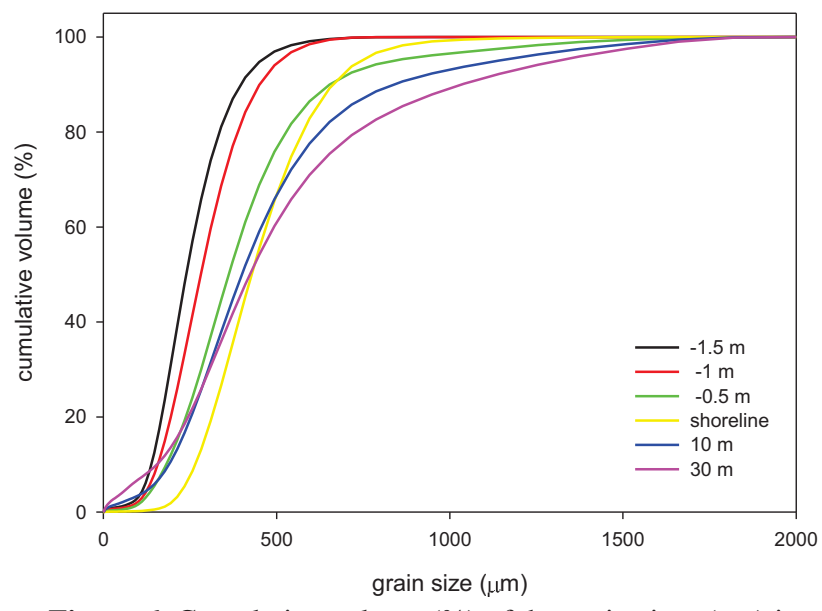

Figure 6. Cumulative volume (\%) of the grain sizes (um) in samples taken at various depths below the shore line and away from the shoreline.

\subsubsection{Subsidence}

Compaction of the sediment layers below the sandy foreshore is occurring due to the newly applied layer of sand. This compaction is approx. $0.1 \mathrm{~m}$ close to the dike where the dike itself has already caused compaction in earlier years (beacons 0, 4, 1 and 6). Further away from the dike the compaction is larger (approx. $0.2 \mathrm{~m}$ ) (beacons 6, 5, 3 and 2) (figure 7). Based on the measurement we conclude that in total approx. $4,800 \mathrm{~m}^{3}$ of sand has been lost out of the pilot ( $\sim 5 \%$ of the total applied volume).

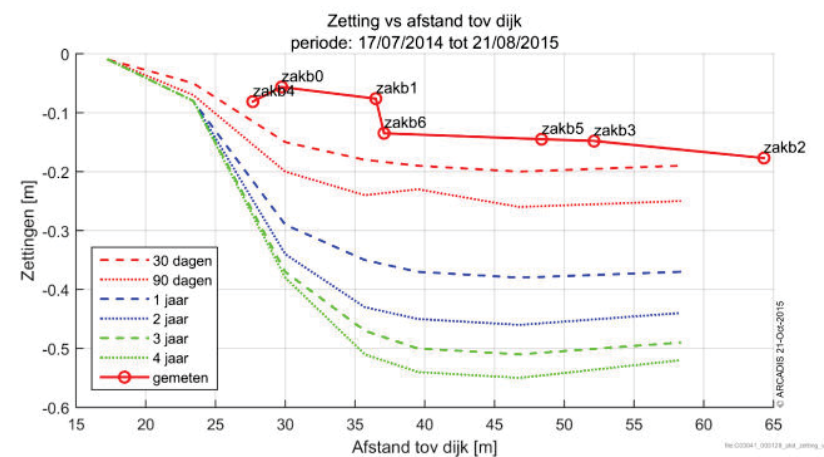

Figure 7 Sediment compaction $(m)$ in distance from the dike (m) for the period to august 2015 compared to the calculated compaction.

\subsection{Vegetation development}

The planted vegetation above the wave impact zone has been able to establish itself well, and is developing faster in the sections where clay was mixed with the sand, as can be clearly seen from the SPOT images NDVI analyses (figure 8).

The areas without planted vegetation have remained bare during this growing season. Only a very limited number of individual annuals were able to withstand the harsh conditions on the pilot and establish themselves to full grown plants above the wave zone. A total of 34 different spontaneously established species were recorded, with 9 of these species on the sandy sections (typically species known for dry conditions) and 17 on the mixed sediment sections (typically species known for 


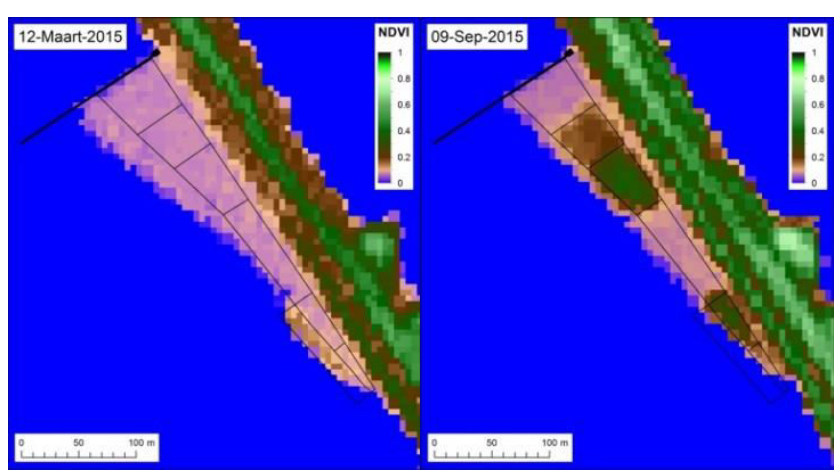

Figure 8 Left figure shows the situation before the vegetation was planted in March 2015, and right figure shows the Normalized Difference Vegetation Index (NDVI) values for the situation with vegetation in September 2015.

more moist conditions). Only 2 spontaneously settled species were found on both the sandy and mixed sections being Common reed (Phragmites australi)s and Golden dock (Rumex maritimus). Most individuals were found in little pockets of more sheltered terrain e.g. behind the wind screen or in the former tracks of the heavy equipment bulldozers used for the construction of the site.

The exclosures had a positive effect on the growth of the vegetation, especially for Common reed plants. The vegetation height in the mixed willow zone was only slightly higher in the exclosure compared with outside the exclosure.

The groundwater levels on the pilot are strongly linked to the water level of the lake (figure 9). With ground water levels of $0.4 \mathrm{~m}$ below the surface close to the water line (P3 and P6) and up to $1.6 \mathrm{~m}$ below the surface close to the dike (P1 and P4). In between this in the middle section of the slope ground water levels fluctuate around $0.8 \mathrm{~m}$ below the surface. The peaks in groundwater level are mainly accounted for by rain events. The reduction in levels in October 2015 is linked to the general water level lowering in the lake from the summer average of $0,2 \mathrm{~m}$-NAP to the winter average of 0.4 m -NAP.

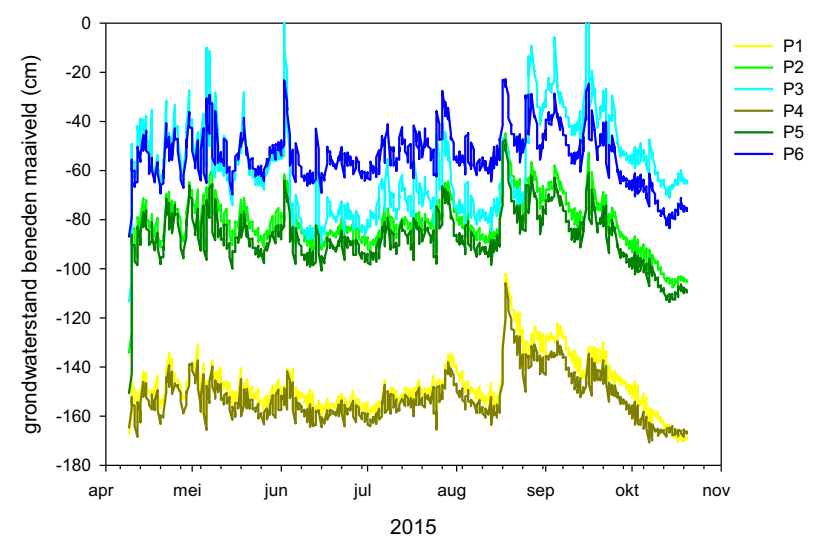

Figure 9. Groundwater levels from April to November 2015 for 6 different ground water divers with $\mathrm{P} 1$ and $\mathrm{P} 4$ close to the dike, P2 and P5 halfway the sections towards the shore line, and P3 and P6 close to the shore line)

\section{Discussion and conclusions}

This pilot shows that constructing new sandy foreshores in front of an existing dike in a large shallow lake is possible. The dynamics on the pilot are greater than expected, which is hampering the establishment of reed vegetation in the shore zone and created a steep $(1: 10)$ and dynamic slope in the shore zone. This slope established itself within the first month after construction. On the areas higher up, the planted willow vegetation is establishing well. The development of Common reed benefits when grazing is limited by exclosures. This vegetation also acts as a wind breaker and allows smaller plants to establish themselves, increasing the biodiversity of the site.

The addition of clay to the sandy top layer has shown to be an effective fertilizer allowing vegetation to develop much faster during the first year compared to the vegetation on only sand.

The groundwater levels on the pilot are strongly linked to the water level of the lake. As a result the pilot is relatively dry on the higher sections, which makes it more difficult for new vegetation to establish. The window of opportunity for successful settlement will be when periods with sufficient rain correspond with the period of germination and initial development.

From a safety perspective the pilot has now been undergoing 1.5 years of normal conditions and is able to withstand these well. However, the extreme conditions that are part of the design criteria have not yet been encountered. Wave heights have already approximated the 1:10 year calculated wave heights of $1.2 \mathrm{~m}$, but this has not occurred together with the calculated maximum water level of $0.55 \mathrm{~m}$ +NAP (max. measured water level has been $0.22 \mathrm{~m}+\mathrm{NAP}$ ). This is probably due to the fact that the reference conditions are assumed to last more hours than the real events encountered so far, causing less wind driven water level set up. It remains therefore difficult to say how this sandy slope will behave under extreme conditions where the water will completely cover a much larger part of the pilot. In order to test such extreme conditions an unscaled flume test is required (also for storms on e.g. a 1:100 or even larger return periods). Also the effect of the vegetation in the higher sections of the pilot as part of the safety solution has not yet been tested. It is hypothesized that the willow vegetation will dampen the incoming waves and reduces erosion of the sediment. The effectiveness of the vegetation in supplying an extra safety layer to the design can therefore not yet been evaluated.

\section{Acknowledgements}

This research is funded by the Dutch Ministry of Infrastructure and Environment under the Innovation fund (theme Building with Nature) of the High Water Protection Programme. We acknowledge Shore Monitoring for carrying out the morphological surveys for this project. 


\section{References}

1. Stark, J., Van Oyen, T., Meire, P., \& Temmerman, S. (2015). Observations of tidal and storm surge attenuation in a large tidal marsh. Limnology and Oceanography, 60(4), 1371-1381.

2. Winterwerp, J. C., Borst, W. G., \& de Vries, M. B. (2005). Pilot Study on the Erosion and Rehabilitation of a Mangrove Mud Coast. Journal of Coastal Research. doi:10.2112/03-832A.1

3. Möller, I., Kudella, M., Rupprecht, F., Spencer, T., Paul, M., van Wesenbeeck, B.K., Wolters, G., Jensen, K., Bouma, T.J., Miranda-Lange, M., Schimmels, S. (2014). Wave attenuation over coastal salt marshes under storm surge conditions. Nature Geoscience, 7, 727-731

4. Smolders, S., Plancke, Y., Ides, S., Meire, P. \& Temmerman, S. (2015). Role of intertidal wetlands for tidal and storm tide attenuation along a confined estuary: a model study. Nat. Hazards Earth Syst. Sci., 15, 16591675.

5. Coops H., Geilen, N., Verheij, H.J., Boeters, R. \& Van der Velde, G. (1996 b) Interactions between waves, bank erosion and emergent vegetation: an experimental study in a wave tank. Aquatic Botany 53, 187-198.

6. Lövstedt, C.B. \& Larson M. (2010). Wave Damping in Reed: Field Measurements and Mathematical Modeling. Journal of Hydraulic Engineering 136, 222-233.

7. Möller, I., Mantilla-Contreras, J., Spencer, T., Hayes, a. (2011). Micro-tidal coastal reed beds: Hydromorphological insights and observations on wave transformation from the southern Baltic Sea. Estuarine, Coastal and Shelf Science, 92, 424-436.

8. Ministry of Infrastructure and Environment, Ministry of Economic Affairs (2015) Deltaprogramma 2015. www.deltacommissaris.nl

9. TAW (2002) Technisch Rapport Golfoploop en Golfoverslag bij Dijken. Delft, May 2002 (Technical report on wave run up and wave over topping for dikes) 